\title{
A COMPARATIVE CYTOLOGICAL AND MORPHOMETRIC ANALYSIS OF VACUOLATION IN CENTRAL TISSUE OF THE EFFECTIVE AND INEFFECTIVE PEA (PISUM SATIVUM L.) ROOT NODULES
}

\author{
WOJCIECH BORUCKI \\ Department of Botany, Faculty of Agriculture and Biology, \\ Warsaw Agricultural University \\ Nowoursynowska 159, 02-776 Warszawa, Poland \\ e-mail: wojciech_borucki@sggw.pl \\ (Received: June 6, 2006. Accepted: October 12, 2006)
}

\begin{abstract}
Vacuoles play very important physiological roles in plant cells. Pea root nodules, which exhibit distinct zonation (meristematic zone and central tissue zones), may serve as a good experimental model for the investigations of vacuole development and its importance to cell and tissue functioning. Moreover, the nodule central tissue is composed of both infected and uninfected cells which play different physiological roles and differ in the level of vacuolation.

Cytological observations revealed that central vacuoles of the infected cells of the effective nodules expand toward cell walls. Thus only thin layers of the cytoplasm separate each central vacuole from plasma membrane and cell wall. This finding is discussed from the viewpoint of improved exchange of solutes and water between the central vacuole and apoplast of the infected cell.

Three-dimensional reconstruction of the vacuoles of infected cells within a fragment of effective nodule central tissue, showed their spatial arrangement. Possible advantages coming from the spatial arrangement of vacuoles within the central tissue are discussed.

A comparative study of the central tissue (bacteroidal tissue) and meristem vacuolation of the effective and ineffective pea root nodules is also presented. Morphometric measurements revealed that the effective nodule central tissue was more vacuolated than the ineffective one. It was proved that maturation of the infected cells involves dynamic changes in their vacuolation. Having numerous fixing nitrogen bacteroids, the infected cells of effective central tissue were less vacuolated than uninfected cells. On the other hand, both infected and uninfected cells of the effective central tissue showed a much higher level of vacuolation in nitrogen-fixing zone than cells of the same type in ineffective tissue. These results indicate that vacuolation is an important factor in development and functioning of pea root nodule central tissue.
\end{abstract}

KEY WORDS: Pisum sativum L., root nodule, central tissue, bacteroidal tissue, vacuolation, morphometry, three-dimensional reconstruction.

\section{INTRODUCTION}

The root nodule of leguminous plants is a unique organ, which develops as a result of many interactions between host plant and rizobia. The meristematic region of the nodule produces cells, which undergo infection by the bacteria released from infection threads, or become uninfected. Bacteria released from the infection threads differentiate into nitrogen fixing bacteroids which form the so-called symbiosomes together with surrounding them peribacteroidal membranes. Up to 20 thousands symbiosomes within one infected cell can be regarded as a new cytoplasmic compartment (Verma and Stanley 1985). Both infected and uninfected cells form the so-called "central tissue" (Vasse et al. 1990; Hirsch 1992; see also Fig. 1) which is also named "bacteroidal tissue".
The infected cells of pea nodules enlarge because of substantial enlargement of their cytoplasm (including symbiosomes) and vacuome volumes (Borucki 1997). The pattern of the infected cell enlargement is not typical as plant cell enlargement is usually a consequence of vacuome enlargement rather than that of cytoplasm (Maeshima 1990; Streeter 1992).

Plant cell differentiation usually involves the development of a large central vacuole, which can occupy more than $80 \%$ of the total cell volume (Fleurat-Lessard et al. 1997). Vacuoles are involved in enhancing the capacity for nutrient acquisition (Raven 1987) and dynamic control of cytosolic pH (Frohnmeyer et al. 1998). Cell vacuolation stimulates cytoplasmic streaming which substantially improves transport of resources within a single cell (Raven 1987). 


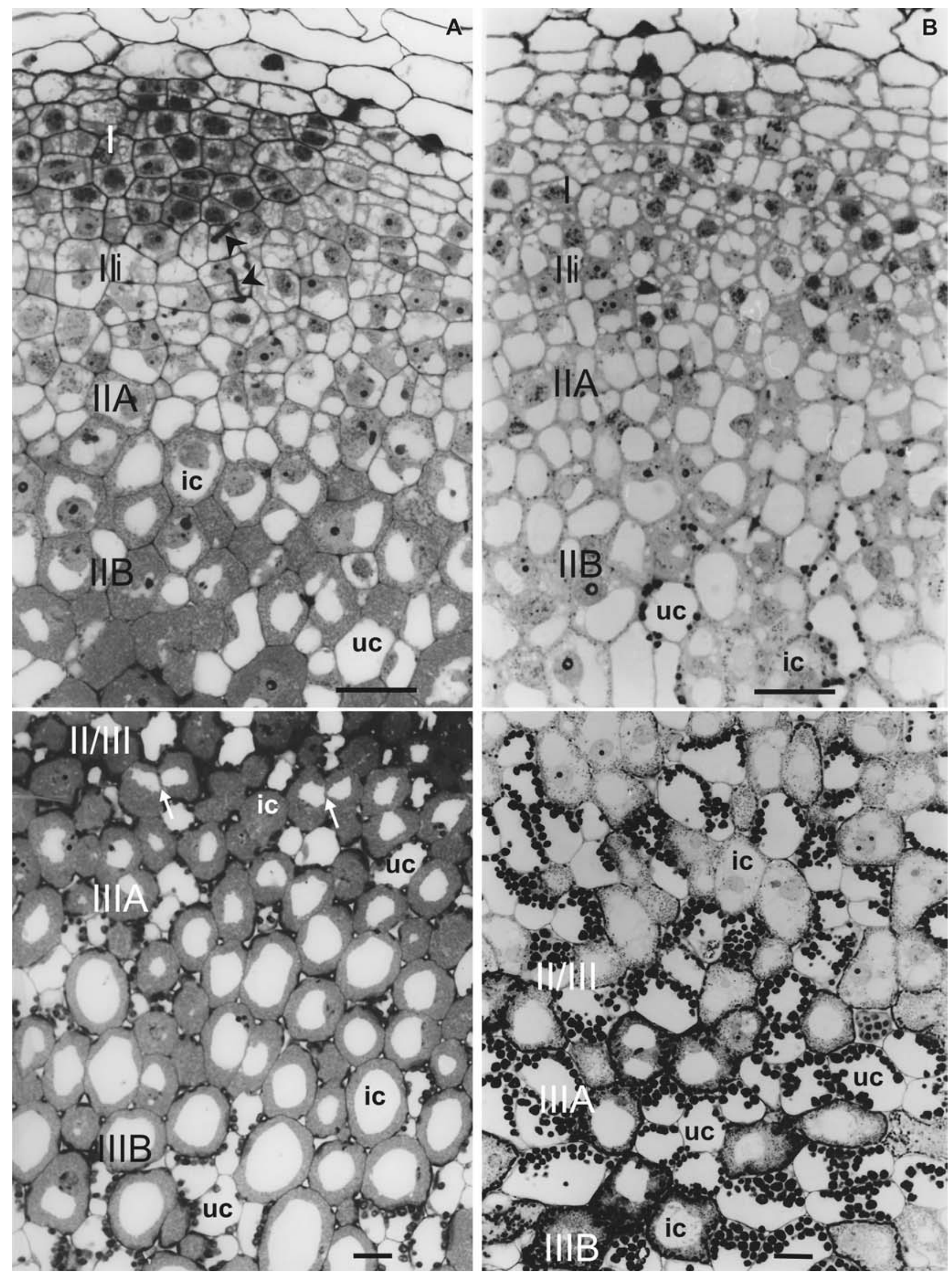

Fig. 1. Longitudinal semi-thin sections showing zonation of the effective (panel A) and ineffective (panel B) pea nodules.

Abbreviations: zone I - nodule meristem; zone II - invasion zone (IIi) as well as distal (IIA) and proximal (IIB) parts of prefixing zone; zone II/III - interzone between prefixing and nitrogen-fixing zone; zone III - distal (IIIA) and proximal (IIIB) parts of nitrogen-fixing zone; $\rightarrow$ central vacuoles of infected cells tend to be located in close vicinity of cell walls; $>$ infection thread; ic - infected cell; uc - uninfected cell. Notice that IIIA and IIIB in panel B represent the ineffective central tissue! Scale bars $=50 \mu \mathrm{m}$. 
In spite of a high cost of plant cell vacuolation, there are many benefits coming from increased area of cell surface per unit volume of cytoplasm of vacuolated cells. Compared with non-vacuolated, vacuolated cells more efficiently absorb ions and metabolites from even low external concentration. There is also an intensive exchange of ions and metabolites between cytosol and central vacuole of vacuolated cells (Raven 1985; Raven 1987). Vacuoles protect cytoplasm from external osmotic shock because tonoplast (vacuole delimiting membrane) has a higher water permeability than plasma membrane (Maurel et al. 1997). On the other hand, high expression of aquaporins in plasma membrane and tonoplast enables quick water fluxes which can control the volume of intercellular spaces responsible for oxygen diffusion (Fleurat-Lessard et al. 2005).

Moreover, vacuolar compartment is not static but undergoes structural, biochemical and functional changes during development of plant cell (Yamamoto et al. 2003; Ngo et al. 2005) or as a response to stress conditions (Johansson et al. 1996; Tyerman et al. 2002). Toxic substances can induce cell vacuolation (Davies et al. 1992). Besides, one plant cell can contain two types of vacuoles for different purposes (storage and lytic, Flückiger et al. 2003; salt storing and malate cycling, Epimashko et al. 2004), which can be distinguishable cytologically (tannin storing and turgor driving, Fleurat-Lessard et al. 1997). These examples show that vacuoles represent dynamic compartments which play important roles in many aspects of plant cell functioning.

Pea root nodules, which exhibit a well defined zonation (see Fig. 1), are used in this work as an experimental model for study of cell and tissue vacuolation. Cytological observations and morphometric measurements were focused on comparisons of vacuolation of the infected and uninfected cells of both the effective (nitrogen-fixing) and ineffective central tissues of pea root nodules. It was proved that maturation of the infected cells exhibits dynamic changes in their vacuolation. Low level of the infected cells vacuolation was proved in this paper by morphometric measurements. This paper describes for the first time the expansion of the central vacuole of the infected cells toward plasma membrane. The structural basis of the specific vacuole adjustment is characterized using light and transmission electron microscopy and three-dimensional reconstruction of the vacuoles within the central tissue. Possible benefits coming from close vicinity of the plasma membrane and tonoplast are discussed.

\section{MATERIALS AND METHODS}

\section{Plant culture}

After sterilization pea seeds (Pisum sativum L. cv. Sześciotygodniowy) were sown in sterile perlite and grown in a growth room at $20-22^{\circ} \mathrm{C}$, with a $16 \mathrm{~h}$ light period (light intensity $\left.400 \mu \mathrm{mol} \times \mathrm{m}^{-2} \times \mathrm{s}^{-1} \mathrm{PAR}\right)$. The plants were watered every three days with nitrogen-free medium according to Fahraeus (1957) and with distilled water on the remaining days.

\section{Inoculation}

Pea plants were inoculated with Rhizobium leguminosarum bv viciae effective strain 248 or ineffective strain RBL1440=248.pRLIJI nifH20::Tn5 (with lack of nitroge- nase activity), both kindly delivered by dr A.H.M. Wijfjes (Institute of Molecular Plant Sciences, Clusius Laboratory, Leiden, The Netherlands). As a result of the inoculation, effective (nitrogen fixing) or ineffective nodules developed on pea roots, respectively. Plants which developed ineffective nodules displayed symptoms of premature senescence. Leaf yellowing of the plants was observed two weeks after inoculation. Most of the plants developed only one pod with 1-2 seeds (not shown).

\section{Materials for light and electron microscopy}

Longitudinal specimens of $\sim 3 \mathrm{~mm}$ long root nodules covered their zones (see Fig. 1) collected from 3-week old pea plants were fixed in Karnovsky fixative (Karnovsky 1965 ) for 3 hours at room temperature. Four washings in cacodylate buffer were followed by a postfixation in $1 \%$ $\mathrm{OsO}_{4}$ at $4^{\circ} \mathrm{C}$, dehydration in ethanol and acetone, and embedding in Epon (Luft 1961).

Longitudinal semi-thin sections ( $2 \mu \mathrm{m}$ thick) through the nodules, stained with methylene blue and azure B were the basis for light microscopy observations and morphometric investigations of the meristem and central tissue. Thin sections were contrasted by the Reynolds method (Reynolds 1963). Observations were conducted by light and transmission electron microscopy using microscope types: Axioskop (Zeiss, Germany) and JEM-100C (Japan), respectively.

\section{Three-dimensional reconstruction}

Reconstruction of the spatial arrangement of infected cell vacuoles was made on a base of serial semi-thin sections of the effective nodule central tissue. Outlines of vacuolar profiles of infected cells were drown on plastic sheets (each $2 \mathrm{~mm}$ thick). After cutting, successive 'layers' of vacuoles were glued together.

\section{Morphometry}

Measurements of the area (volume) occupied by vacuoles and cytoplasm of the infected and uninfected cells of the central tissue were done using computerized image analyser (AnalySiS version 3.0; Olympus; Japan) on the basis of semi-thin sections (6 sections from different nodules per meristem or central tissue zone; 8 images per section; objective $40 \times$ or $100 \times$ ). In order to achieve a high contrast between vacuoles and cytoplasm a green interference filter was used. Then a semi-automatic procedure included: drawing the outline of the central tissue or the infected and uninfected cells separately; green colour separation and grey values modification, in order to achieve very bright and very dark areas representing vacuoles and cytoplasm, respectively; image binarization; detection of vacuoles; automatic measurements of the area (volume) fraction occupied by vacuoles and equivalent circle diameter (ECD) of the profiles of infected and uninfected cells.

Cell walls were not distinguished from the cytoplasm under light microscopy. Thus, cell vacuolation was defined as a fraction of cell volume occupied by vacuoles. Tissue vacuolation was defined as a fraction of tissue volume (without intercellular spaces) occupied by vacuoles.

\section{Statistical analysis}

Data were analysed statistically by analysis of variance (ANOVA) for comparison of means. ANOVA was used to test for differences in the percentage of vacuolation of tis- 

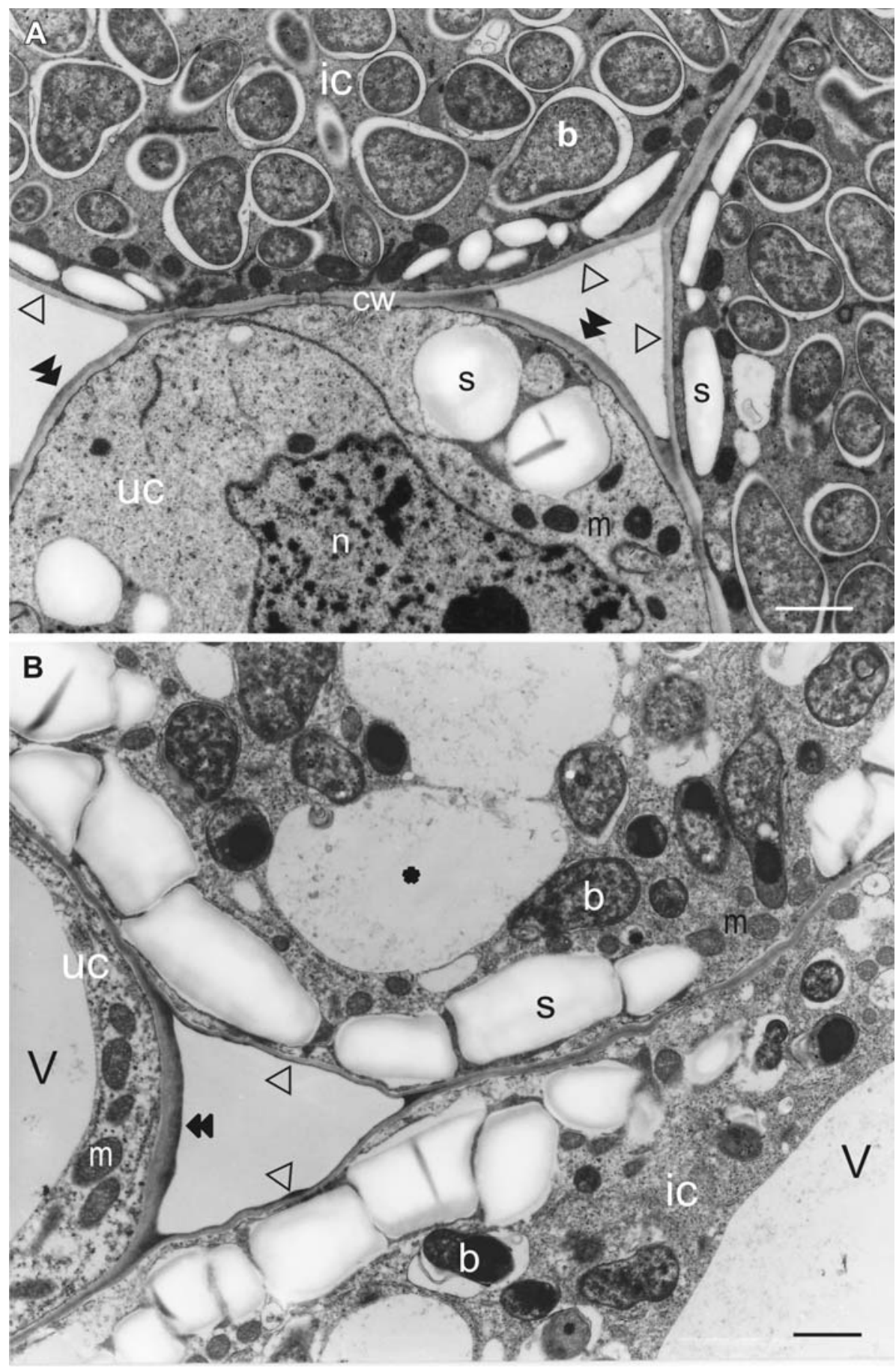

Fig. 2. Comparisons of the effective (A) and ineffective (B) central tissue (zone III) fragments of pea nodules. Abbreviations: ic - infected cell; uc - uninfected cell; $b$ - bacteroid; $\mathrm{m}$ - mitochondrium; $\mathrm{n}$ - nucleus; $\mathrm{s}$ starch granule; $\mathrm{V}$ - central vacuole; $\mathrm{cw}$ - cell wall; double arrowhead - thick cell wall; $\triangleright$ thin cell wall; $\star$ small vacuole. Scale bars $=2 \mu \mathrm{m}$.

Notice the differences in morphology of bacteroids and starch accumulation within the infected cells. Thick and thin cell wall fragments adjacent to intercellular spaces are marked. sues or cells from each nodule zone $(P<0.05$, Tukey's test) and differences in the percentage of vacuolation of effective and ineffective tissues or cells in each zone $(P<0.05$, Student's test). The percent data were arcsin square rooted (Bliss transformation) before analysis (Zar 1996).

\section{RESULTS}

\section{Structural observations}

Pea nodule zonation according to Vasse et al. (1990) with modification given by Hirsch (1992) (Fig. 1)

Meristematic cells (zone I) have distinct nuclei and contained many small vacuoles. Divisions of meristematic cells led to the formation of nodule central tissue (zones II, II/III and III).
The periphery of nodule meristem was penetrated by infection threads which contained rizobia (Fig. 1A). This part of the nodule named invasion zone was marked in this paper as IIi.

The central tissue, located adjacent to IIi, comprised the prefixing zone (IIA and IIB), interzone (II/III) and nitrogen-fixing zone (IIIA and IIIB). The tissue consisted of infected (IC) and uninfected (UC) cells. ICs contained rizobia released from the infection threads and differentiated into bacteroids.

Prefixing and nitrogen-fixing zones of effective nodules were separated by interzone (II/III), which was characteristic by large starch deposits in both the infected and uninfected cells (Fig. 1A). Distal part of the prefixing zone adjacent to IIi was named in this paper zone IIA and proximal part neighboring to interzone was named zone IIB. The ni- 

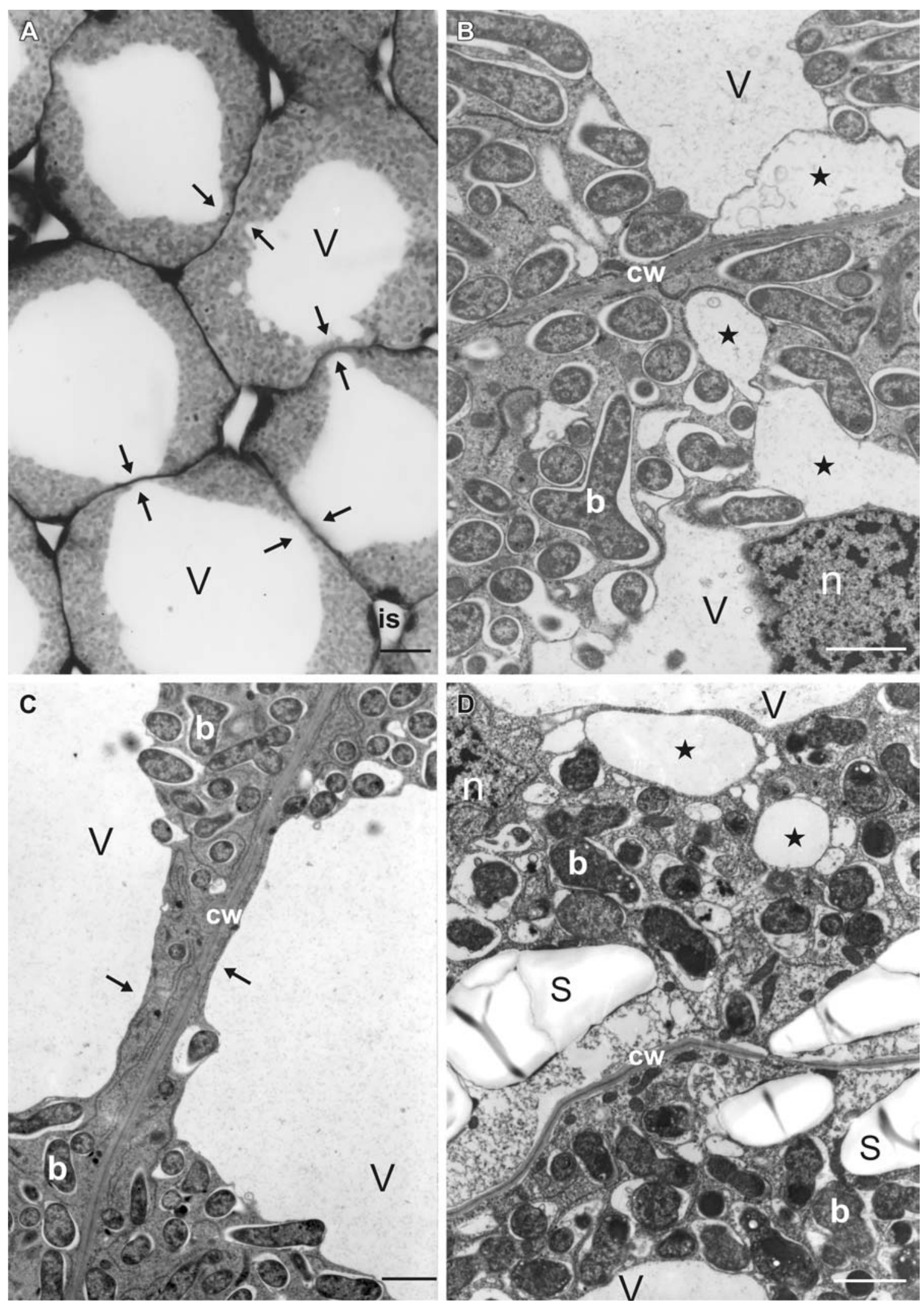

Fig. 3. Spatial arrangement of central vacuoles of the infected cells of the nitrogen-fixing zone. A, B and C - effective infected cells; D - ineffective infected cells. A - central vacuoles of the infected cells expand toward cell walls; B - small vacuoles develop between central vacuole and plasma membrane; $\mathrm{C}$ - only thin layer of cytoplasm separates tonoplast and plasma membrane; D - large amyloplasts can block expansion of central vacuoles toward cell walls.

Abbreviations: $\mathrm{b}$ - bacteroid; $\mathrm{n}$ - nucleus; $\mathrm{s}$ - starch granule; $\mathrm{V}$ - central vacuole; $\mathrm{cw}$ - cell wall; is - intercellular space; $\rightarrow$ vacuoles develop toward cell walls; $\star$ small vacuoles. Scale bars: (A) $10 \mu \mathrm{m}$; (B, C and D) 2 um.

trogen-fixing zone was also divided into distal and proximal parts: zone IIIA and zone IIIB, respectively.
The same zonation was applied to the ineffective central tissue (Fig. 1B), but it should be stressed that zone III of 

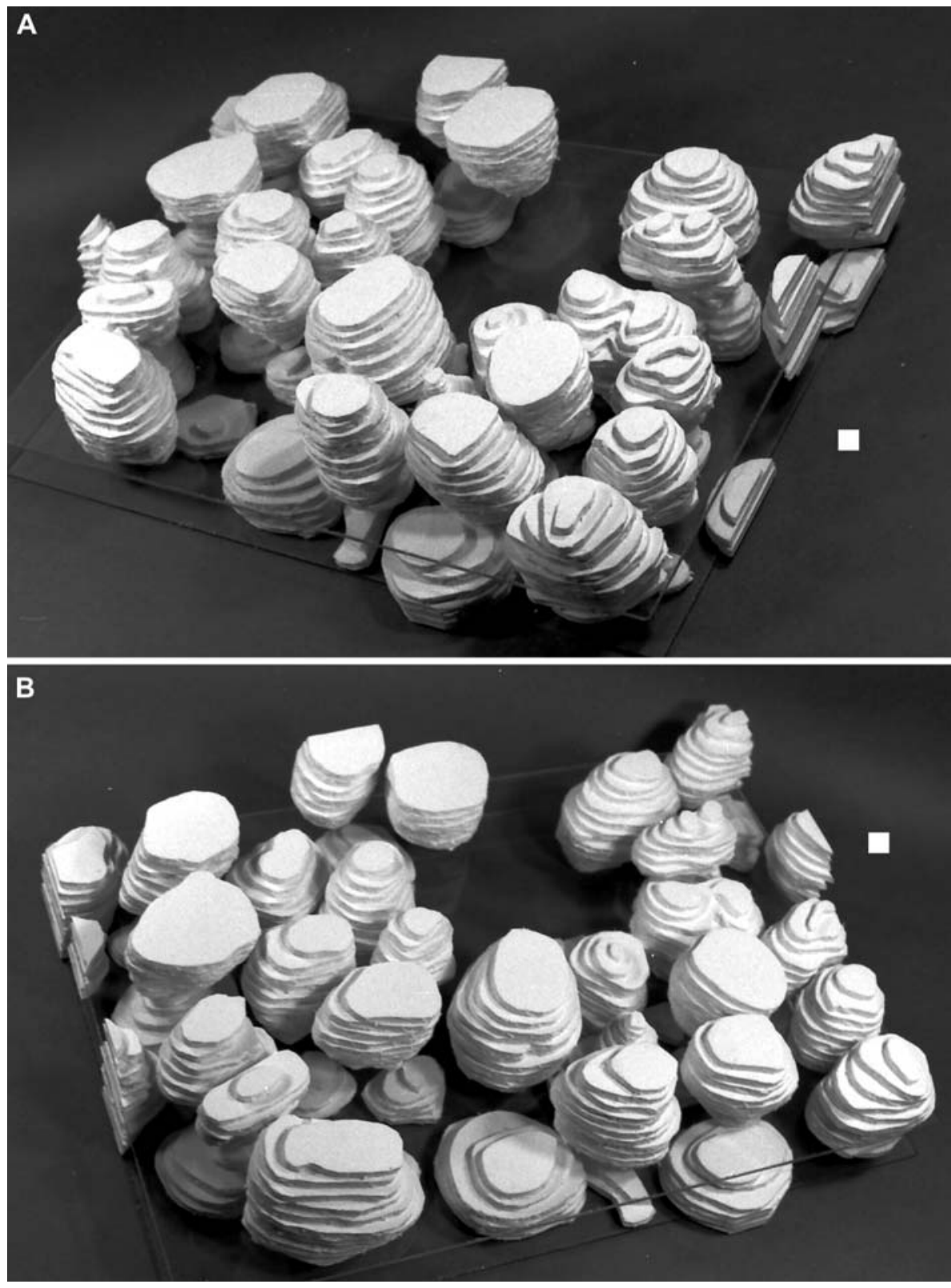

Fig. 4. Three-dimensional reconstruction of central vacuoles of the infected cells from the effective, nitrogen-fixing zone. (A) and (B) show different views on the same model. White squares mark the same side of the model. Notice that vacuoles of the infected cells get in close contact with vacuoles of neighbouring cells.

the tissue did not fix nitrogen. Because of intensive starch accumulation in ineffective nodule central tissue, strict location of zones II/III, IIIA and IIIB in the tissue was often problematic. In opposition to the effective, the ineffective central tissue was characteristic by starch accumulation in the uninfected cells of zones IIA and IIB.

Starch accumulation and morphology of bacteroids of the effective and ineffective central tissue (Figs 1-3)

Both the infected and uninfected cells accumulated starch. In case of the effective central tissue, amyloplasts containing starch granules were located predominantly adjacent to the intercellular spaces (Figs 1A and 2A). Abundant starch accumulation and location of amyloplasts all around the cell periphery were characteristic features of the infected cells of the ineffective central tissue (Figs 1B and 2B). Differences in morphology of bacteroids between the effective and ineffective central tissues were observed. Electron-dense regions characterized cytoplasm of the bacteroids from ineffective nodules (compare Figs 2A and 2B; Figs 3B and 3D).
Uninfected cells of zone III of both the effective and ineffective nodules developed thicker wall fragments adjacent to the intercellular spaces than did the infected cells (Fig. 2).

Vacuolation of the infected cells (Figs 1 and 3) and three-dimensional reconstructions of their vacuoles (Fig. 4)

Small vacuoles visible in the meristematic cells fused, what resulted in the formation of the central vacuole in each infected and uninfected cell (Fig. 1). Central vacuoles of infected cells of the effective central tissue expanded toward cell walls (Figs 1A and 3A, zone IIIA). Small vacuoles developed between the central vacuole and plasma membrane of the infected cells (Fig. 3B). Only a thin layer of cytoplasm (even $\sim 0,2 \mu \mathrm{m}$ thick, calculated from Fig. 3C) separated tonoplast, vacuole delimiting membrane, from plasma membrane. Spatial reconstruction also showed that central vacuoles of neighbouring infected cells were separated from cell walls by only thin layers of cytoplasm (Fig. 4).

In case of the ineffective central tissue, expansion of central vacuoles of infected cells toward cell walls was restricted (Fig. 3D). 


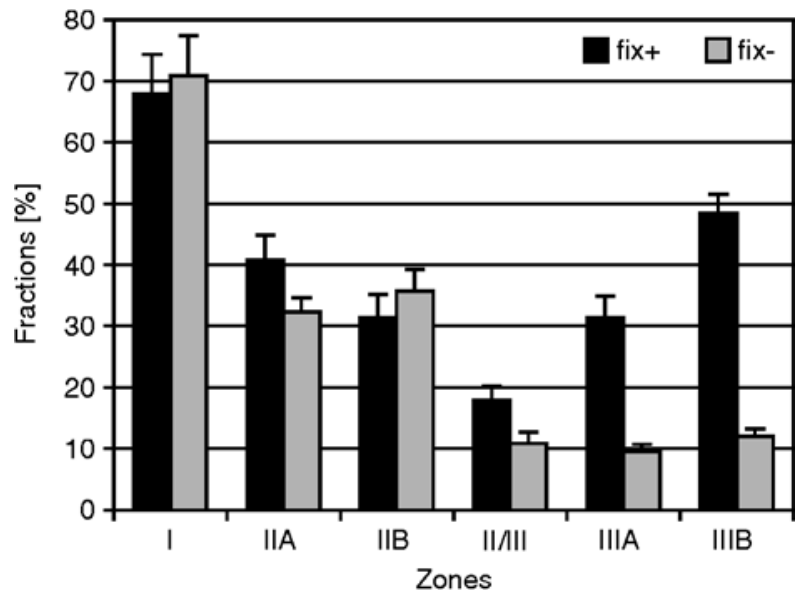

Fig. 5. Fractions (\%) of meristematic zone (zone I) and central tissue zones (zones II-III) occupied by vacuoles. For zonation see Figure 1. Abbreviations: (fix+) meristematic and central tissues of effective nodules, (fix-) meristematic and central tissues of ineffective nodules. Each value is a mean \pm S.D. of 6 determinations performed on 6 randomly chosen nodules $\sim 3 \mathrm{~mm}$ long. Overlapping S.D. values show that differences between means do not differ significantly at $P<0.05$.

\section{Morphometric measurements}

\section{Vacuolation of tissues (Fig. 5)}

Vacuoles occupied ca $70 \%$ of meristematic tissues of both the effective and ineffective nodules. First, vacuolation of the effective central tissue decreased reaching minimal value $(\sim 18 \%)$ for interzone II/III. Then vacuolation of the tissue started to increase and reached maximal level $(\sim 48 \%)$ in zone IIIB. The pattern of the ineffective central tissue vacuolation was different as it had constant value ( $10 \%)$ from interzone II/III to zone IIIB.

A rapid decline in the central tissue vacuolation was observed between zones IIB and II/III of both the effective and ineffective nodules. In interzone II/III, the effective central tissue was substantially more vacuolated than the ineffective central tissue. In the zones IIIA and IIIB the effective central tissue was from 4 to 5 times more vacuolated than ineffective one.

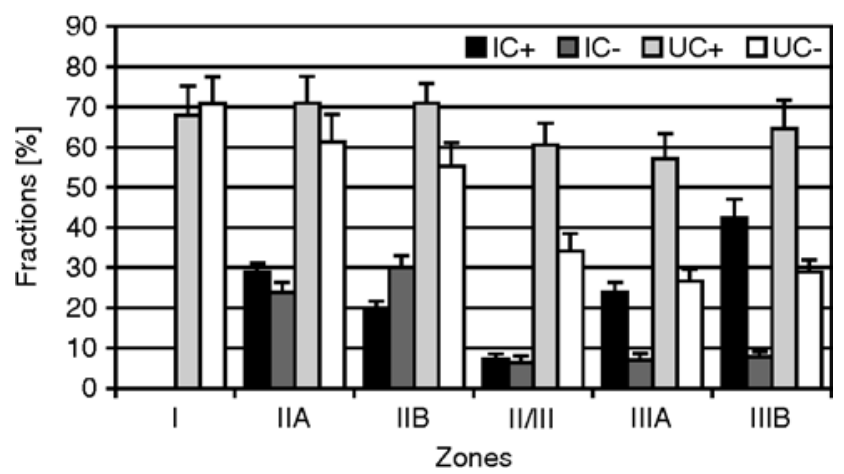

Fig. 6. Fractions (\%) of the infected (IC) or uninfected (UC) cell volumes of the effective (+) or ineffective (-) central tissue (zones II-III) or meristem (zone I) occupied by vacuoles. For zonation see Figure 1. Each value is a mean \pm S.D. of 6 determinations performed on 6 randomly choosen nodules $\sim 3 \mathrm{~mm}$ long. Overlapping S.D. values show that differences between means do not differ significantly at $P<0.05$. Notice that vacuolation of UC+ varies between $65-75 \%$ and that of UC- gradually decreases from 70 to $30 \%$. No differences in the level of vacuolation of IC+ and IC- are observed in zones IIA and II/III. Vacuolation of IC+ is much higher than IC- in zones IIIA and IIIB. Distinct differences in the level of vacuolation of infected and uninfected cells are observed in zones IIIA and IIIB.

\section{Infected or uninfected cell vacuolation (Fig. 6)}

Uninfected cells of the effective central tissue (UC+) were more vacuolated than ineffective (UC-) in all distinguished zones. Vacuolation of the uninfected cells varied from 60 to $70 \%$ for effective central tissue and gradually decreased from 60 to $30 \%$ for ineffective central tissue.

In case of infected cells of the effective central tissue (IC+), represented by a much higher level of vacuolation than the cells of the ineffective central tissue (IC-) in zones IIIA and IIIB. It should be stressed that infected cells of the effective central tissue showed increased vacuolation within the two zones, adversely to the same kind of cells in the ineffective central tissue (IC-).

Fractions of meristematic and infected or uninfected cells of the central tissue occupied by cytoplasm or vacuoles (Fig. 7)

Cytoplasm and vacuole volume fractions of the infected and uninfected cells were expressed separately for the effective and ineffective central tissue. The volume of uninfected cell cytoplasm (UCc) comprised about $10 \%$ of the effective and ineffective tissue volume except that for zone IIIB of the ineffective tissue.

The infected cells comprised from 70 to $80 \%$ of the effective central tissue and from 75 to $90 \%$ of the ineffective central tissue volume. Cytoplasm of the infected cells gave less contribution to the volume of the effective central tissue than ineffective, especially in zones IIIA and IIIB.

\section{Equivalent circle diameter (ECD) \\ of meristematic and central tissue cells (Fig. 8)}

Substantial increase in ECD values of the infected cells of the effective central tissue was observed especially between zones IIIA and IIIB. A significant increase in ECD values for the uninfected cells of the effective central tissue (UC+) was observed in zone IIIB only.

A slow increase of ECD values for both the infected (IC-) and uninfected cells (UC-) characterized the ineffective central tissue development.

ECD values of the infected cells of the effective central tissue $(\mathrm{IC}+)$ exceeded these for the ineffective central tissue (IC-) in zone IIIB. Uninfected cells of the effective central tissue $(\mathrm{UC}+)$ were characterized by lower ECD values in interzone II/III and zone IIIA, comparing with these for the ineffective central tissue.

\section{DISCUSSION}

The effective pea root nodules showed distinct cytological zonation (Fig. 1A). In particular, interzone II/III of the effective central tissue, characterized by abundant starch accumulation and low level of vacuolation of infected cells (Fig. 6), was distinguishable from zones II and III. In case of the ineffective nodules, this zonation was not clear because of continuous starch accumulation within their central tissue. Thus, interzone II/III could not be easily separated from zones II and III of the ineffective central tissue (Fig. 1B). These findings indicated that the process of the ineffective central tissue differentiation was perturbed.

Cytological observations revealed that central vacuoles of the infected cells located in the distal part of zone IIIA of the effective nodules, which occupied a small fraction of 
A

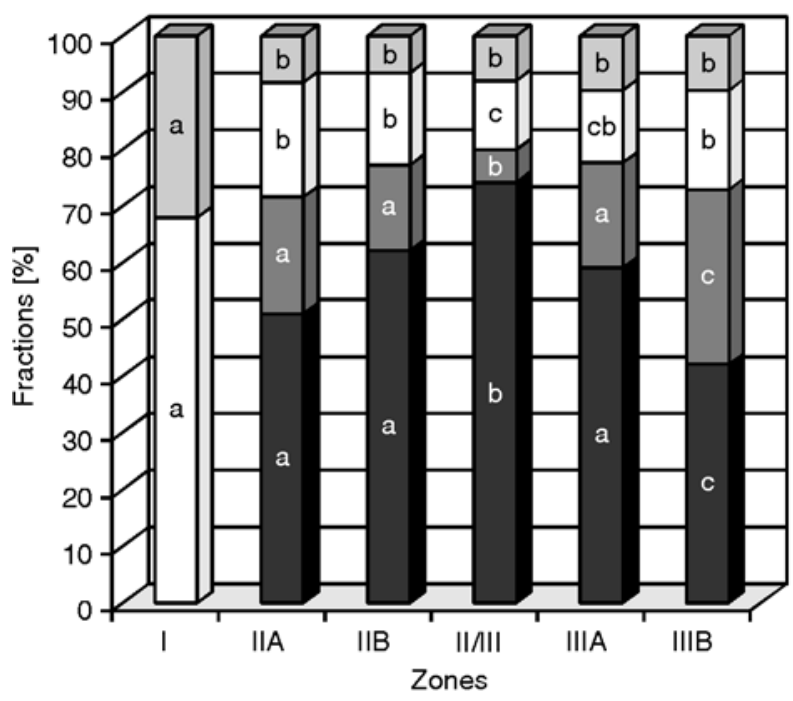

B

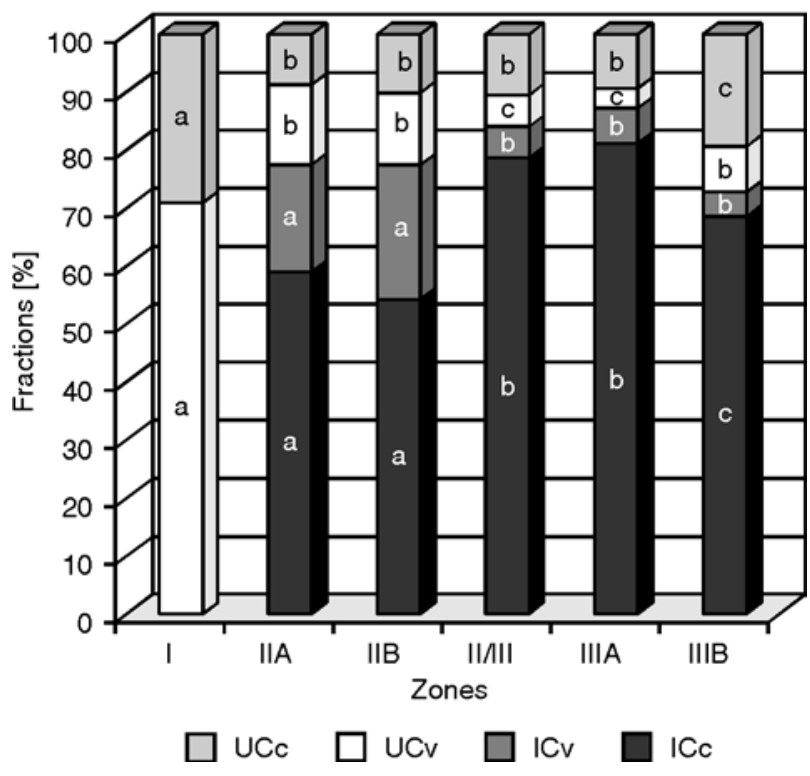

Fig. 7. Fractions (\%) of meristem (zone I) or central tissue zones (zones II-III) occupied by cytoplasm of uninfected cells (UCc), vacuoles of uninfected cells (UCv), cytoplasm of infected cells (ICc), vacuoles of infected cells (ICv). A - meristematic and central tissues of effective nodules; B meristematic and central tissues of ineffective nodules. For zonation see Figure 1. Each value is a mean of 6 determinations performed on 6 randomly chosen nodules $\sim 3 \mathrm{~mm}$ long. Means followed by the same letter, within the same compartment (UCc, UCv, ICc or ICv), do not differ significantly at $P<0.05$.

the cell volume (Figs 6 and 7), tended to be in close vicinity of the cell wall (or plasma membrane!) (Fig. 1A). It suggests that the position of the central vacuoles is important for functioning of the infected cells. Besides, the central vacuoles of the effective infected cells showed a different shape than that of ineffective ones (Figs 3 and 4). The unusual shape of vacuoles of the effective infected cells with a kind of "outgrowths" resulted from their expansion toward cell walls and was a characteristic feature of this type of cells. The development of the outgrowth involved formation of small vacuoles between central vacuole and plasma membrane. Than the small vacuoles fused with the central vacuole (Fig. 3). As a result of these processes, only a thin layer of cytoplasm separated tonoplast from

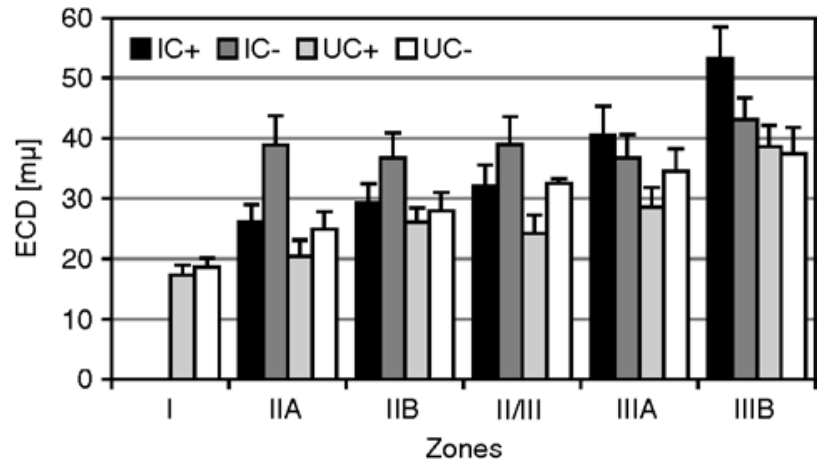

Fig. 8. Equivalent circle diameter (ECD) values of the infected (IC) or uninfected (UC) cell profiles of the effective (+) or ineffective (-) meristem or central tissue. For zonation see Figure 1. Each value is a mean \pm S.D. of 6 determinations performed on 6 randomly chosen nodules $\sim 3$ $\mathrm{mm}$ long. Overlapping S.D. values show that differences between means do not differ significantly at $P<0.05$. Notice that ECD values of $\mathrm{IC}+$ gradually increase but that of IC- are constant. Except II/III interzone no significant differences between ECD values of UC+ and UC- are observed.

plasma membrane. So, the close vicinity of the two membranes is probably of great importance for functioning of infected cells. In addition, the reconstruction of vacuoles of infected cells within a fragment of the effective central tissue (zone III) revealed that they form a three-dimensional system which can improve functioning of the tissue (Fig. 4). The system can be involved in long distance transportation of resources within the central tissue. It can improve the transcellular pathway of water and solutes transportation, proposed by Steudle and Frensch (1996), because it requires the involvement of transportation across plasma membrane and tonoplast. Vacuolar content gives less resistance to the diffusion of substances than that of dense cytoplasm of the infected cells and can be beneficial for such a way of long distance transportation.

Several advantages coming from close vicinity of plasma membrane and tonoplast were proposed. Robinson et al. (1996) postulated that invaginating domains of the plasma membrane called plasmalemmasomes containing high concentration of aquaporins might be responsible for accelerating exchange of water between the apoplast and the vacuole. The authors made the assumption on a base of the observation that plasmalemmasomes can protrude some distance into the vacuole, at those areas where the cytoplasm forms only a thin layer. Plasmalemmasomes were not observed in the infected cells of pea root nodules, but location of infected cell vacuole in the vicinity of plasma membrane probably improves transport of ions and water between them and apoplast. High abundance and variety of aquaporins in plant membranes underlines the importance of water balance for plant cells, tissues and organs (Kjellbom et al. 1999; Karlsson et al. 2000; Baiges et al. 2002). Also, rapid turgor variations in response to external stimuli, characteristic for motor cells of Mimosa pudica (FleuratLessard et al. 1997), may depend on close vicinity of tonoplast of the central vacuole and plasma membrane. But, low expression of aquaporins in plasmalemma and tonoplast of infected cells of soybean root nodules rather excludes rapid water fluxes and turgor changes in these cells (Fleurat-Lessard et al. 2005).

Another explanation of vacuolar expansion toward cell walls can be the necessity of efficient signal exchange be- 
tween plasma membrane and tonoplast. Propagation of signal in the form of elevated concentration of $\mathrm{Ca}^{2+}$, first close to plasma membrane and subsequently adjacent to the vacuole, was found in guard cells following application of abscisic acid (Allen et al. 1999).

Morphometric measurements revealed perturbations in vacuolation of the ineffective central tissue. Compared with effective tissue, the level of the ineffective central tissue vacuolation was from 3 to 5 times lower in zones IIIA and IIIB (Fig. 5). It resulted from a substantial decrease in the level of vacuolation of both infected and uninfected cells (Fig. 6). In opposition to the effective tissue, no increase in the level of the ineffective central tissue vacuolation was observed between zones II/III and IIIB. So, in case of ineffective central tissue, zone III could not be distinguished from interzone II/III on the basis of tissue vacuolation. It appears, that zones IIIA and IIIB of ineffective central tissue can be regarded as widened interzone II/III.

Infected cells of the effective central tissue (zones IIIA and IIIB) were vacuolated only in about $40 \%$ (Fig. 6). The level of the infected cell vacuolation in case of the ineffective central tissue (zones IIIA and IIIB) was about 4 times lower (Fig. 6). The low fraction of infected cells of the ineffective central tissue occupied by vacuoles coincided with abundant starch accumulation. On the other hand, amyloplasts having large starch granules were distributed all around the periphery of the infected cells of the ineffective central tissue (Fig. 1B and 3D) and probably disturbed in expansion of vacuoles toward cell wall. Strict correlation between low level of vacuolation and high starch content was also visible in interzone of the effective central tissue (Fig. 1).

In zones IIIA and IIIB, vacuoles of the infected cells gave higher contribution to the effective than ineffective tissue. Compared with the infected cells, variability of the vacuolar volume of the uninfected cells to the effective central tissue volume was much lower (Fig. 7A). So, changes in total vacuolation of the effective central tissue depended mainly on vacuolation of the infected cells. Compared with the effective central tissue, vacuoles of both the infected and uninfected cells gave much less contribution to the ineffective central tissue volume in zones IIIA and IIIB (Fig. 7B). It emphasizes the importance of vacuolation for the functioning of nitrogen fixing pea nodules.

Comparisons of ECD values (Fig. 8) of the effective infected cells with their vacuolation (Fig. 6) led to the conclusion that the cells enlarged first, because of the cytoplasm volume enlargement (zones IIA-II/III), and then maturation of the cells involved an increase of the vacuolar volume rather than that of cytoplasm (zones IIA and IIB). The pattern of uninfected cell enlargement of the effective central tissue was different, because the cells enlarged as a result of simultaneous increase of the cytoplasm and central vacuole volumes.

No increase of ECD values of infected cells of the ineffective central tissue was proved statistically between zones IIA and IIIB. Since at the same time the vacuolation of the cells decreased, it means that their cytoplasm volume increased at the expense of vacuolar volume. An enlargement of uninfected cells of the ineffective central tissue was observed from zone IIA to zone IIIB, mainly as a result of the cytoplasm volume enlargement because vacuolation of the cells substantially decreased.

\section{CONCLUSIONS}

Cytological observations and morphometric measurements showed different patterns of the infected and uninfected cell vacuolation and enlargement during development of the effective and ineffective central tissues of pea nodules. The importance of vacuolation to cell differentiation and establishment of the central tissue effective in nitrogen fixation was proved in this work. It appears that the shape and spatial arrangement of central vacuoles are important in the central tissue functioning. Further investigations, including stress conditions which disturb cell vacuolation, might provide more information about physiological significance of shape and arrangement of central vacuoles within the central tissue.

\section{ACKNOWLEDGMENTS}

The author thanks Ewa Znojek for preparation of the microscopic material.

\section{LITERATURE CITED}

ALLEN G.J., KWAK J.M., CHU S.P., LLOPIS J., TSIEN R.Y., HARPER J.F., SCHROEDER J.I. 1999. Cameleon calcium indicator reports cytoplasmic calcium dynamics in Arabidopsis guard cells. Plant J. 19: 735-747.

BAIGES I., SCHÄFFNER A.R., AFFENZELLER M.J., MAS A. 2002. Plant aquaporins. Physiol. Plant. 115: 175-182.

BORUCKI W. 1997. Structural bases for effectivity of bacteroidal tissue in pea root nodules formed by effective or ineffective bacteria strain. Acta Soc. Bot. Pol. 66: 165-176.

DAVIES K.L., DAVIES M.S., FRANCIS D. 1992. Zinc-induced vacuolation in meristematic cells of cereals. Ann. Bot. 69: 21-24.

EPIMASHKO S., MECKEL T., FISCHER-SCHLIEBS E., LÜTTGE U., THIEL G. 2004. Two functionally different vacuoles for static and dynamic purposes in one plant mesophyll leaf cell. Plant J. 37: 294-300.

FAHRAEUS G. 1957. The infection of clover root hairs by nodule bacteria studied by a single glass slide techniques. J. Gen. Microbiol. 16: 374-381.

FLEURAT-LESSARD P., FRANGNE N., MAESHIMA M., RATAJCZAK R., BONNEMAIN MARTINOIA E. 1997. Increased expression of vacuolar aquaporin and $\mathrm{H}^{+}$-ATPase related to motor cell function in Mimosa pudica L. Plant Physiol. 114: 827-834.

FLEURAT-LESSARD P., MICHONNEAU P., MAESHIMA M., DREVON J.-J., SERRAJ R. 2005. The distribution of aquaporin subtypes (PIP1, PIP2 and $\gamma$-TIP) is tissue dependent in soybean (Glycine max) root nodules. Ann. Bot. 96: 457-460.

FLÜCKIGER R., DE CAROLI M., PIRO G., DALESSANDRO G., NEUHAUS J.M., DI SANSEBASTIANO G.P. 2003. Vacuolar system distribution in Arabidopsis tissues, visualized using GFP fusion proteins. J. Exp. Bot. 54: 1577-1584.

FROHNMEYER H., GRABOV A., BLATT M.R. 1998. A role for the vacuole in auxin-mediated control of cytosolic $\mathrm{pH}$ by Vicia mesophyll and guard cells. Plant J. 13: 109-116.

HIRSCH A.M. 1992. Developmental biology of legume nodulation. New Phytol. 122: 211-237.

JOHANSSON I., LARSON C., EK B., KJELLBOM P. 1996. The major integral proteins of spinach leaf plasma membranes are putative aquaporins and are phosphorylated in response to $\mathrm{Ca}^{2+}$ and apoplastic water potential. Plant Cell 8: 1181-1191.

KARNOVSKY M.J. 1965. A formaldehyde-glutaraldehyde fixative of high osmolarity for use in electron microscopy. J. Cell Biol. 27: 137A. 
KARLSSON M., JOHANSSON I., BUSH M., MCCANN M., MAUREL C., LARSSON C., KJELLBOOM P. 2000. An abundant TIP expressed in mature highly vacuolated cells. Plant J. 21: 83-90.

KJELLBOM P., LARSSON C., JOHANSSON I., KARLSSON M., JOHANSON U. 1999. Aquaporins and water homeostasis in plants. Trends Plant Sci. 4: 308-314.

LUFT J.M. 1961. Improvements in epoxy resin embedding methods. J. Biophys. Biochem. Cytol. 9: 409.

MAESHIMA M. 1990. Development of vacuolar membranes during elongation of cells in mung bean hypocotyls. Plant. Cell. Physiol. 31: 311-317.

MAUREL C., TACNET F., GÜCLÜ J., GUERN J., RIPOCHE P. 1997. Purified vesicles of tobacco cell vacuolar and plasma membranes exhibit dramatically different water permeability and water channel activity. Proc. Natl. Acad. Sci. USA 94: 7103-7108.

NGO D.A., GERLAND P.A., MANDOLI D.F. 2005. Development and organization of the central vacuole of Acetabularia acetabulum. New Phytol. 165: 731-746.

RAVEN J.A. 1985. Regulation of $\mathrm{pH}$ and generation of osmolarity in vascular plants: a cost-benefit analysis in relation to efficiency of use of energy, nitrogen and water. New Phytol. 101: 25-77.

RAVEN J.A. 1987. The role of vacuoles. New Phytol. 106: 357$-422$.

ROBINSON D.G., SIEBER H., KAMMERLOHER W., SCHÄFFNER A.R. 1996. PIP1 aquaporins are concentrated in plasmalemmasomes of Arabidopsis thaliana mesophyll. Plant Physiol. 111: 645-649.

REYNOLDS E.S. 1963. The use of lead citrate at high $\mathrm{pH}$ as an electron opaque in electron microscopy. J. Cell. Biol. 17: 208$-213$.

STREETER J.G. 1992. Analysis of apoplastic solutes in the cortex of soybean nodules. Physiol. Plant. 84: 584-592.

STEUDLE E., FRENSCH J. 1996. Water transport in plants; role of the apoplast. Plant Soil. 187: 67-79.

TYERMAN S.D., NIEMIETZ C.M., BRAMLEY H. 2002. Plant aquaporins: multifunctional water and solute channels with expanding roles. Plant Cell. Environ. 25: 173-194.

VASSE J., DE BILLY F., CAMUT S., TRUCHET G. 1990. Correlation between ultrastructural differentiation of bacteroids and nitrogen fixation in alfalfa nodules. J. Bacteriol. 172: 4295-4306.

VERMA D.P.S., STANLEY J. 1985. Molecular interaction in endosymbiosis between legume plants and nitrogen-fixing microbes. Ann. New York Acad. Sci. 503: 284-294.

WALSH K.B. 1995. Physiology of the legume nodule and its response to stress. Soil Biol. Biochem. 27: 637-655.

YAMAMOTO Y., NISHIMURA M., HARA-NISHIMURA I., NOGUCHI T. 2003. Behavior of vacuoles during microspore and pollen development in Arabidopsis thaliana. Plant Cell Physiol. 44: 1192-1201.

ZAR J.H. 1996. Biostatistical analysis. 3rd ed. Prentice-Hall International, Inc., pp. 282-283. 